\title{
Qualitative Exploration Of Violence Against Women (VAW) Regarding Social And Cultural Trends Among Women In Pakistan
}

\author{
Seema Manzoor \\ $\&$ \\ Dua-e-Rehma \\ Women's Studies \\ University of Pakistan \\ Naheed Abrar \\ Department of Social Work \\ Federal Urdu University Karachi
}

\begin{abstract}
Violence against women (VAW) and women issues have appeared to be growing threat for women globally, especially violence against women are causing severe social and health problems due to social and cultural trends. Many researchers have been involved in conducting research so far, but root causes and solutions are not yet explored to eradicate the issue. This study is an attempt to provide a clear understanding of the qualitative exploration of violence against women regarding social and cultural trends among women in Pakistan. By using qualitative research method researcher has analyzed different factors and circumstances which these women are experiencing. For this purpose case studies research methods is used to analyze specific issues within the boundaries of a specific environment and situation, because case study research method is explanatory, descriptive and exploratory in nature. In this study five case studies are incorporated to access the history and current scenario regarding violence against women in Pakistan by using unstructured interview schedule. Two hospitals (private and government) were selected as a universe of the study, and the respondents were purposively selected for conducting interviews in detail. The findings of this study reveal that the respondents have faced many types of violence all through their life, which includes psychological and physical abuse by males within or outside the family, which includes hitting, slapping and shoving and other social evils like honor killing, rape, incest, acid throwing and burning and etc. It is about high time and the need of the time for media and health professionals along with the public sector to highlight the problems at mass level and to take up the challenge for appropriate actions to curtail highly prevailing social evil (VAW).
\end{abstract}

Keywords: Violence against Women, Social and Cultural Trends, Exploitation, Physical and Sexual Abuse. 


$$
\begin{aligned}
& \text { تلخيص }
\end{aligned}
$$

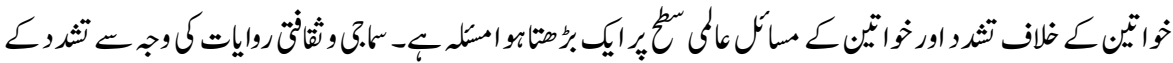

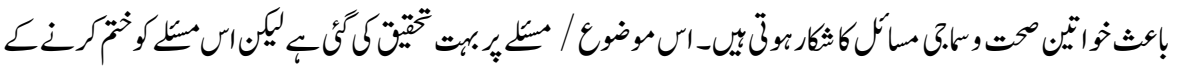

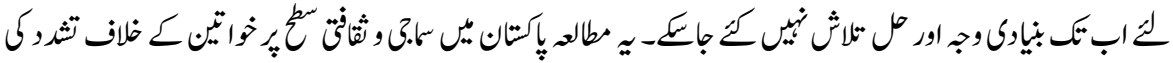

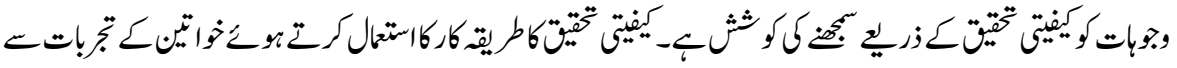

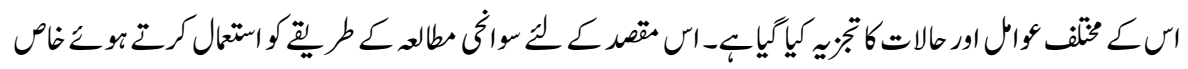

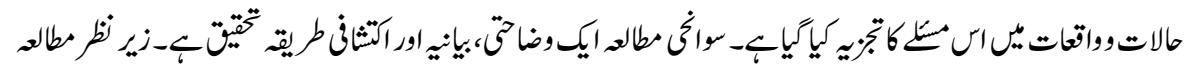

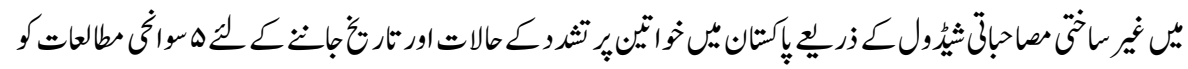

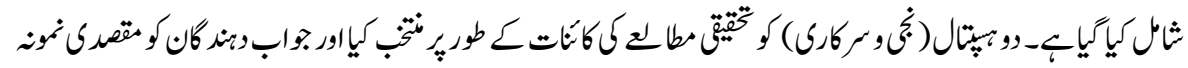

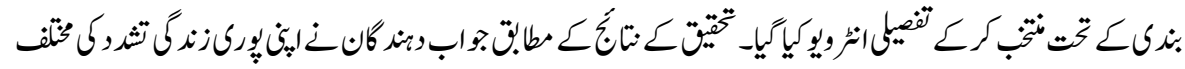

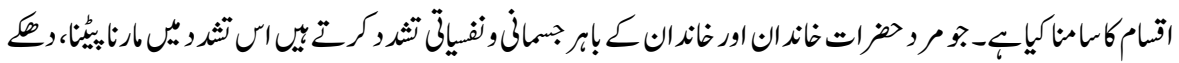

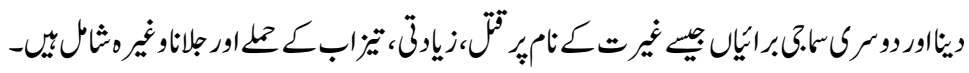

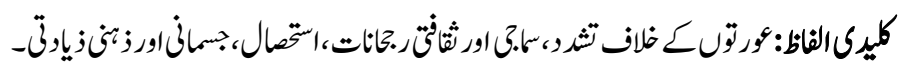

\section{Introduction}

"Violence against women is perhaps the most shameful human rights violation, and it is perhaps the most pervasive. It knows no boundaries of geography, culture or wealth. As long as it continues, we cannot claim to be making real progress towards equality, development and peace." (Kofi Annan, 1999)

The performance and perception of violence regarding social context are of key significance. Usually humiliation, insults and harsh arguments are taken as normal attitude, but it is a violation of the rights of other human beings and it might be termed as "senseless violence". Such kind of violence is practiced to control others by using repugnant use of power. In some cases it has been observed that violence takes the form of ritual, for example, ill treatment with women and children is considered as routine and it is practiced continuously therefore, it takes the shape of social ritual. Since violence is a way of imposing power on others, therefore, women being submissive in nature become easy victim and its nothing new Ahuja (1998), because it is an imbalanced relation between a perpetrator and the victim, i.e. between man and woman, which leads to inequality and discrimination against women to stop them from gaining empowerment 
(General Assembly, 1993). WHO defines violence as deliberate actions used to apply physical force against a person, group or community, which has a high probability of causing injuries, harming psychologically, or can even cause death in extreme cases (WHO, 1996). Women become easy victims of violence throughout the world, because they are neglected, thus the cultural framework, which is designed by dogmatic thoughts of the patriarchal social system. Low social status of women enhances their submissive role; therefore, as a result, it has become a normal societal behaviour. The aggression and hostile attitude towards women in growing even in the $21^{\text {st }}$ century, which is intensifying the existing issues; thus, depriving women in gaining access even to basic resources.

Violence against women can be categorized in a wide variety of forms, which includes domestic violence in all existing forms, girl child abuse (within and outside the family), female infanticide, rape, incest, sexual assault, neglecting the rights of old women, violence by intimate partner, forced marriage, child marriage, prostitution and etc. According to the recent researches the trend of violence against women is constantly increasing, though many laws have been formulated at the national and international level. This situation clearly indicates that more efficient efforts towards the reduction and control of violence against women in needed (CIC, 2010). Many researchers have argued that violence against women is a major social issue; therefore, it needs special attention for its resolution in order to deal with all the emotional consequences linked to it (Ali and Gavino, 2008). Women also face domestic violence usually from their intimate partners, which affects women physically, mentally and negligence of social well-being as well (Gender Equity Program, 2012). In the past two decades the issues related to domestic violence and its consequences in Pakistani culture have been recognized Khan (2009), therefore, women's rights groups have become more active and their sustained efforts are attending the issue (U.S. Department of State, Human Rights, 2010). Researchers from different regions and cultures are attempting to highlight the main causes more closely to examine the perceptions and social attitudes, which is causing its prevalence. The social practices and influences due to cultural setup should also be addressed to curtail the issue, because without understanding the root causes the issue cannot be resolved.

The range of psychological, physical and sexual coercive actions by a male intimate partner is generally known as violence against women (WHO, 1997). Globally VAW is considered as the most insidious and unrecognized violation of human rights in the form of abuse. There are some alternate terms used for domestic violence, which can be listed as:

- Courtship violence

- Intimate partner violence

- Domestic abuse

- Domestic violence

- Wife battering 
- Marital rape

- Spouse abuse (Saltzman, 1999).

Many researches have been conducted so far on various aspects of this issue, but still it is very difficult to analyze the level of its prevalence due to the discrepancy regarding the definition of the subject. VAW is still not addressed the way it should be, therefore it is needed to universalize some standard facts and definitions Raphael (2000). The studies, which have been conducted so far, lack in epidemiological factor that is why the eradication of violence has become a very difficult task (Bradley, 2002). The global statistics show that one out of every three women faces violence of different types in her marital life at certain points. According to the records, almost $10-69 \%$ women have been assaulted physically during their lifetime by their male partner (Krug, 2002). Rennison commented that only in USA, wife battering act is very common, it occurs very often and even women are murdered in violence acts (Rennison, 2003). Research literature examination shows that violence cases are usually based on cultural setup and socially constructed roles.

According to WHO estimates, 35 percent face physical or sexual violence at some point of their lives either by their intimate partners or by other males. Whereas, some national studies show that the estimates are up to 70 percent. Women who are abused by their partners are more prone to have depression or abortion in case of pregnancy (WHO, 2013). Violence against women is a global issue and it is prevailing in all societies, but still exact data is not available. Violence causes women to face psychological issues. Even in western and European countries 43 percent women face psychological violence by their intimate partners (European Union Agency for Fundamental Rights, 2014). Some other studies show very alarming situation regarding violence against women that the majority of women are even killed by their partners after abuse and violence (United Nations Office on Drugs and Crime, 2014). Early marriages also contribute as a key factor and it is estimated that globally 750 million women are married before their eighteenth birthday. Early marriage trend is more common in developing nations. Child marriage results in early and repeated pregnancies, which cause severe reproductive health issue and high trend is seen in the form of the maternal mortality rate. Early marriages deprive girls from getting education and also marginalize them from socializing, which increases the tendency of domestic violence (UNICEF, 2017).

In Pakistani culture, domestic violence is taken as a family matter or a private matter; therefore, it is not easy to assess the actual statistics of the victims (Fikree \& Bhatti, 1999). Pakistani women suffer due to discrimination and violence because of religious and cultural norms (Bettencourt, 2000). According to human rights watch estimates in Pakistan, 70-90\% women face domestic violence (Human Rights Watch, 1999). Domestic violence has a wide range and its many forms are not even considered as 
violence, but they affect women mentally, psychologically, emotionally and physically. HRCP conducted a survey in Punjab in 2000; the findings indicated that $35 \%$ women were hospitalized, because they were brutally beaten by their husbands. Only in Punjab $70-90 \%$ women face spousal abuse. Women are either beaten on petty issues or face various forms of violence from their husband and in-laws (HRCP, 2000). Another study was conducted in Pakistan showed that most of the women face physical violence, which causes them severe psychological problems. Honor killing is very common in both rural and urban setups; the Karo-Kari custom is practiced in various parts of Pakistan. According to official statistics during the period 1998- 2004, 2800 women out 4000 cases died as a result of violence acts. Research statistics reveal that in Larkana, Sindh, KaroKari is a very common practice and almost all the victims are women (Felix, 2007). These researches indicate that in Pakistan, violence against women is a very sensitive yet massive issue in the public and social domain, but unfortunately this issue has never been appropriately addressed by the government.

In 2015, White Ribbon Pakistan gave statistics regarding violence against women in all the provinces of Pakistan. In 2015, VAW cases were reported in Punjab were as follows: 2,720 rape cases, 173 honor killing cases, 22 acid throwing cases, 35 burning cases and 588 wife battering cases. Similarly, the VAW cases reported in Khyber Pakhtunkhwa in 2015 are 20 attempted to rape cases, 32 gang rape cases, 987 honor killing cases, whereas, violence cases in different cities of KPK are as follows: 104 in Peshawar, 35 in Mardan, 14 in Kohat and 11 violence cases in Mansehra. Almost same figures are seen in Sindh province, for example 344 rape and gang rape cases, 860 honor killing cases, 90 acid throwing cases, 72 burning cases and 535 cases of domestic violence. Like other provinces Balochistan also show high trends in VAW, for instance 939 cases of rape, gang rape, stripping and harassment, 143 cases of burning acid throwing and 279 cases of domestic violence were reported (White Ribbon Pakistan, 2015).

HRCP revealed that 2,300 women were killed in Pakistan in the name of honor killing in past few years i.e. from 2014 - 2016. It added that now the government has taken some serious measures towards violence issues, but instead of decrease in these cases, trends show that this social evil is constantly increasing. According to the HRCP, it seems that all the efforts of the government are in vain. Human rights commission of Pakistan shows an overview of violence cases from 2004 - 2016, for instance 4,734 cases of sexual violence, 15,222 cases of honor killing, 1,535 cases of burning, 1,843 cases of domestic violence, 35,935 cases of suicide and 5,508 cases of kidnapping (HRCP, 2016). Pakistani women are somewhat trapped in socio-cultural norms and violence is used against them as a tool to maintain patriarchy. Agha in his study claimed that as per gender inequality index Pakistan ranks 143 out of 144 countries (Agha, 2017). 


\section{Types of Violence}

VAW is unbridled globally, especially in the developing countries. Violence in all forms deprives women of their rights. Violence victims feel helpless, because they cannot seek help from any forum. Many laws have been made and implemented, but no fruitful results are obtained. There are uncountable factors causing the prevalence of violence and violence can be categorized in many ways.

\section{Acid Burning and Dowry Death}

Women's position is suppressive in all spheres of life; especially married women face many issues due to the intervention of in-laws in her life and relationship with her husband. If a woman disobeys any command of her in-laws or husband then she becomes the victim of their revenge: acid is thrown on her face or body or she is burned to death. Similarly, if the bride's parents are unable to give the demanded dowry then in such cases usually the in-laws punishes her by violence and sometimes she is beaten to death (Khatun, 2012).

Different statistics show that acid throwing cases have increased in Pakistan and the majority of victims are females. Almost 150 acid burning cases are reported every year, which is a result of revenge against women, who refuses the marriage proposals and due to some other reasons. Domestic violence is also increasing due to illiteracy, poverty and some socio-cultural issues. Women are not even safe in their homes, instead of having peaceful life they live a miserable life in pain and fear. Domestic violence can occur due to many factors like early marriage, dowry and etc. Dowry deaths are very high in India, Bangladesh and Pakistan. India has the highest rate of dowry death and in Pakistan 2,000 dowry deaths are reported each year. It has been observed that unjust societal attitude and gender inequality are the main causes of women issue (Feroz, 2017).

\section{Honor Killing}

Women are considered as the pride of the family or the custodian of the family's name. Therefore, if they are found involved in any immoral activity, for example, having illicit relationship, then they have to face worst form of violence by their husband, father or brother. Even innocent women are accused for such immoral activities, the reason behind this accusation is to gain benefit for the family by sacrificing daughters (Naved, 2013).

In March 2015, the Anti-Honor Killing Laws (Criminal Amendment Bill) 2015 and the Anti-Rape Laws (Criminal Amendment Bill) 2015 were finally passed by the joint sitting of both houses of parliament; these bills were presented by Sughra Imam (PPP legislator) which were pending for a long time. Though these bills were passed by the parliament, 
but were not implemented properly. After a massive increase in violence incidents against women like Nazia Hameed in Kasur, Ambreen in Abbottabad, Maria Sadaqat in Murree and the murder of Qandeel Baloch by her brother, the government took initiative and some serious measures to control these issues (Zaidi, 2016).

\section{Domestic Violence}

It is the violation of human rights, i.e. depriving women from accessing their rights and resources. It is the ultimate responsibility of government to protect women from domestic violence and when the state fails to do so it means that the state becomes ineffective in fulfilling their moral obligation (Khan and Aeron, 2006).

In 2015, the government of Punjab initiated a Punjab Protection of Women Against Violence Bill 2015, which faced massive opposition but was ultimately passed by the Punjab Assembly. This bill is a very comprehensive regarding the protection of women against all forms of violence and criminal activities like domestic abuse, emotional and psychological abuse, feminization of poverty cyber crime and stalking and etc. this bill aimed to curtail violence against women and provide them justice in order to empower them (Hanif, 2016).

\section{Violations of Human Rights}

Cultural norms, values are strictly imposed to maintain sexuality. The community along with all its pillars like, religion, family, culture and media control women and punish them if they do not follow the rules and regulations set by the society (Naved, 2013).

HRCP in its annual report 2016 highlighted the ratio and percentage of violence cases against women. Asma Jahangir, the spokesperson of HRCP claimed that violence against women is the clear violation of human rights. She added that in Gilgit, Baltistan, KPK, Balochistan, Sindh and Punjab the rate of honor killing is constantly increasing. Besides the legislation the cases of violence against women are not declining, because women are dependent on men; they do not have the economic independence and a high percentage of women is involved in low wage work, where they are exploited by the employer. More than $30 \%$ women are employed in the industrial sector. Similarly, they lack in the education field as compared to males. HRCP claimed that 2,500 women became the victims of various forms of violence in 2016 (HRCP, 2016).

\section{Immediate Causes of Violence}

Gender violence shows the attitude and behaviour of humans and they are deep rooted. The main reason of VAW appears to be the low economic and social status of women, 
which brings dire consequences of violence, because they cannot seek any help from any societal sector. Women face violence of many forms within the family also which includes: incest, forced marriage, abuse by an intimate partner, control over their body and decisions and etc. the worst thing is, the violence women face within the family is considered as a form of protection of women (Yasmin, 2000). Basically, this social attitude is adopted to have control of women's lives and it is the denial of their basic human rights, which deprives them from taking advantage of the designated rights.

\section{Acid Assault}

Acid assault cases involve the male ego and lack of understanding in acceptance towards the rights and choices of women as humans. Usually women become victim of acid throwing due to refusing love, marriage proposal and sometimes family problems. According to the studies, in most of the acid throwing cases reasons were unknown and majority of the cases were related to sterility, family disputes, refusing forced sexual relationship, dowry and women's disagreement to husband's second marriage (Begum and Shiplu, 2013).

\section{Community Violence}

Community violence has many reasons based on societal roles and attitudes. Religious beliefs also play a very important role in it, because people depict meanings of their choice and desire from the religious rulings. Women who are willing to marry by their choice also face community violence, because society bounds women to live according to the social code of conduct, which have been designed to have complete control over their lives (Agarwal, 1988).

\section{Intermediary Causes of Violence}

Dowry: Though legislation to prohibit dowry transaction exits, but still it is greatly prevailing in our society. Demand of dowry has become a legitimate element of finalizing marriage through parley. Begum (2013) argues that dowry is not a simple issue; it starts from discussion then turns to verbal abuse, battering, violence and agony which in most of the cases finally lead to the death of a victim (bride).

Lack of Education: Illiteracy makes women more susceptible to social evil practices, through findings of various researches it has been identified that education can reduce the prevalence of violence, however, there is no clue how violence can be reduced through education (Hadi, 2010). Education provides awareness to women regarding their rights and privileges, thus making them less prone to violence and other anti-human activities. Unlike Hadi, Khan and Aeron (2006) identified that education definitely impact women's life, though it may not change the traditional roles within the household setup. But it 
definitely makes women less dependent on males by providing them self-esteem, and decision making power. It might not affect their lives directly, but plays a vital role in overcoming the patriarchy through women's autonomy and power.

Lack of Security: Women face lack of security in all spheres of life, especially those women who are engaged in productive or academic activities. Majority of these women use public transport for travelling and they face security issues along with harassment, therefore, lack of security can be linked to travelling somehow. Women who travel through public transport casually for household routines or travel from the workplace, needs to have the facility of safe travelling, especially when travelling at night. But unfortunately working women are usually not provided any transport facility at official level, which makes them suffer from travel hazards and they face violence and harassment while travelling back home at late hours (Khan and Aeron, 2006).

\section{Underlying Causes}

Poverty: Poverty is considered as the main root cause of many social evils. Economic instability of a household increases the tension, which could lead to violence (Jahan, 1994). Similarly, Kabeer (1998) states that violence may be practiced in a systematic or random manner, is related to poverty thus, leading to powerlessness. Lack of basic necessities and resources in poor families enhances the intensity of violence due to extreme frustration.

Child Marriage: Child Marriage Restraint Act, 1983 is implemented to control the issue, but still child marriage is observed. Girls are considered as a burden for the family, therefore, parents marry them off as soon as possible, and some girls get married even before their puberty age. Parents marry off their young girls, because they think they might bring shame to the family name if they get involved with someone (Azim, et al., 2002). Early child marriage also enhances violence in marital life; whereas, a mature woman is a bit protective, because the huge age gap between spouses develops an unequal relationship. Thus, creating mistrust between them and leads to disharmony marital relationship.

Religious Obstinacy: The religious rigidity is a result of community based violence is committed against an individual of the same community. Beating, torturing or humiliating women is prohibited is Islam, it is the influential element of society (the so called religious leaders) who provokes people to act violently against women to keep them submissive and to control their self-determination, bodies and sexuality in order to maintain their patriarchy. If a man and woman, both are found involved in an illicit relationship, then woman and her family are punished severely than man and his family or he can get away with it by paying off some penalty. Such extreme cases complicate the situation and women become more powerless and submissive (IWRAW, 2005).

Islam has given clear rulings regarding the roles, rights and responsibilities of both men and women. Allah has clearly mentioned in Quran that men and women both are equal in their humanity and good deeds. In the Quran the first verse of Surah Al-Nisa, Allay says: 
"O mankind, fear your Lord, who created you from one soul and created from it its mate and dispersed from both of them many men and women. And fear Allah, through whom you ask one another, and the wombs. Indeed Allah is ever, over you, an Observer". (4:1)

In Surah Al-Nisa, verse: 34, the term "Qawwam" is used, which means to support, protect and supervise. In Islam men have more responsibilities regarding socio-economic obligations. The prime responsibility of man is the maintenance of women, according to the Islamic Law. Women have no liability to support their families in economic terms; they are free from such social, economic and political responsibilities. Islam has given more freedom to women as compared to men, for instance regarding economic liabilities Quran says:

"Men will have a share of what they earn, and women will have a share of what they earn" (4:32).

The Quran refers men superior in terms of their role as "Qawwam" by fulfilling their responsibility of providing maintenance, protection and supervision. Men are superior to women only in terms of responsibilities. In Islam the family system is based on societal and social structure and in order to maintain the natural discipline every man and woman has to play their role according to Islam. In the Quran, Allah says:

"Men are guardians and managers over women" (4:34).

Subordination of Women: On religious and cultural grounds our society considers women as subordinates of men; therefore, men can treat them according to their desire. The violence shows an unequal hierarchy between the victim and the perpetrator, which enables men to dominate women. Through violence women are forced to adopt submissive nature to satisfy man's ego. It is a critical social mechanism which makes men superior over women (Jahan, 1994).

\section{Theoretical Framework}

Many researchers and authors have proposed theories to elucidate the VAW phenomenon. Violence against women exists in many forms and women abuse has multiple features; therefore, a single theory cannot cover the issue completely (Dasgupta, 2001). Edleson has quoted the concepts of Brofenbrenner regarding violence against women from his widely read books, which were published in late 70's and 80's (Edleson, 2000). Similarly, Belsky has also used the Brofenbrenner's concepts like many authors to explain the details of many social evils Belsky (1980), for example child abuse, domestic violence etc. (Heise, 1998). It is further elaborated as a framework which shapes the behaviour through social interaction between individuals. This interaction leads to development in terms of different stages of social organization (Dutton, 1994). This framework offers five stages, individualism, meso-system and exo-system, micro-system and macro-system (Edleson, 1992). Individualism provides personal and biological aspects, which triggers the behaviour of an individual, and the 
micro-system encircles the workplace issues and family (Carison, 1984). The link between a person's micro-systems is provided by the meso-system stage of the framework. Whereas, the relation between the social system and structure regarding the person's social living is explained by exo-system. Lastly, the role of cultural background on wider level is encompassed by the macro-system.

Since feminism advocates the women's rights; therefore, feminist theories view social issues as consequences of patriarchal societies. Feminists argue that woman abuse is due to the existing patriarchal setup, which keeps women in servile state. According to the feminist standpoint through social change things can be changed, i.e. when women start raising their voice against violence (Gondold and Fisher, 1988). Bandura believes that social learning theory is an arrangement of perpetration and acceptance principle and the level of psychological and physical abuse is examined through aggressive actions against the target (Campbell and Humphreys, 1993). Another theory, i.e. exchange theory appears to be the alternate of learning theory and it suggests that the assaulters hit people, because they have power or authority to do such actions. For the perpetrators, violence is a way to have control on other people (Galles and Cornell, 1985).

\section{Framework for Establishing Perception about VAW}

In the world health report typology of violence is presented in three broader categories to highlight how violent acts are committed: a) self-directed, b) interpersonal and c) collective violence (WHO, 2002). Along with that, it also highlights the nature and intensity of violent acts, i.e. sexual, physical, and psychological, etc. this report has overviewed the nature of violence faced by both men and women of different ages. Interpersonal violence is mainly considered most common type of violence faced by women globally and it can be imposed by an individual or group of people. Therefore, interpersonal violence is further divided into two subdivisions, i.e. by family or by community, within or outside the home. Usually girls in their childhood and adolescence period or mature women face interpersonal violence and this type of violence is imposed to control their lives. Violence against women is outlined and indicated in the figure below:

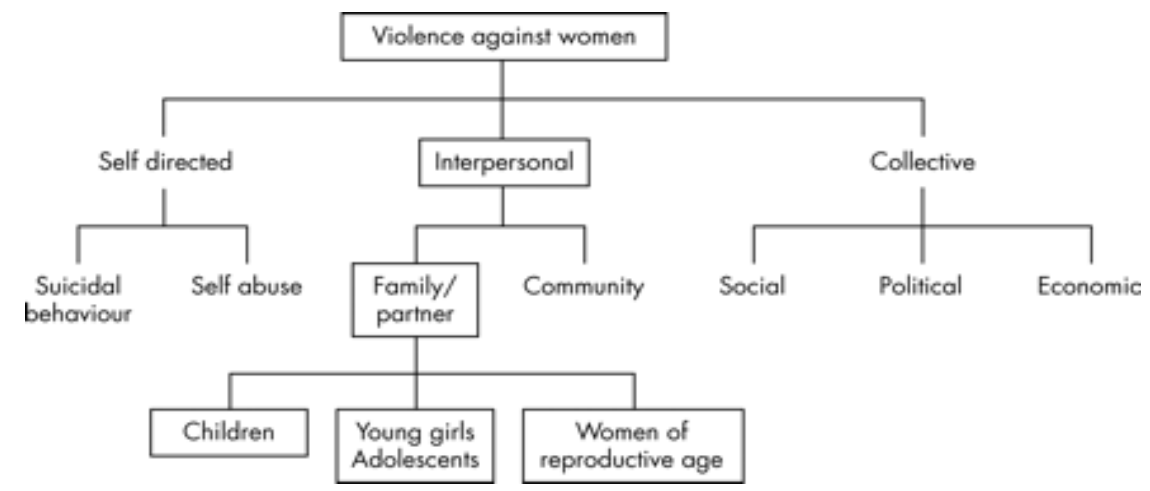

Source: Flow chart of VAW typology, altered on the basis of WHOs world report on violence and health (WHO, 2002). 


\section{The Nature of the Violent acts}

Violent Aimportant to note that whether violence is self-directed, interpersonal or collective, it involves sexual, physical and psychological abuse. The situation becomes more complex and intense when these forms interrelate to each other and as a result complex behaviour pattern is shown, i.e. physical or sexual abuse might combine with psychological violence under some specific circumstances. According to Coker, women who face both sexual and physical violence suffer from severe health issues than women who face physical violence only. He concluded that sexual violence might cause severe violence impact on women and can also escalate violence acts (Coker, 2000).

Physical violence: It is basically exercising physical aggressiveness through aggressive acts like strangling, kicking, hitting, beating or slapping. Injuries caused due to such aggressive acts are disguised as accidents. These injuries can cause serious health issues and can even cause death (Ellsberg, 1999). Various studies show that between 10\%-60\% women are beaten or face physical abuse by their intimate partners (Heise, 2002). Domestic violence by an intimate partner is prevailing in the society, because the effected female hesitate to share, therefore it is not possible to find out accurate figures.

Psychological, mental, or emotional violence: This type of violence indicates the humiliation and frustration women face through restrictions like preventing them from seeing friends and family, economic dependency, threatening and sharing healthy conversations with the persons they like. This type of violence cannot be easily characterized on the basis of countries or cultures, because it varies from place to place and culture to culture (Maxwell \& Blair, 2015). For example, a husband may force his wife to spend time with other males Jewkes (2002), or confining her within the home and not letting her to meet other people is considered as an emotional violence (Watts, 2002). Sexual violence: In sexual violence, physical force is used against the victim for sexual assault or exploitation, which can transmit sexually transmitted diseases, because such perpetrators do not use safe methods for forced sex. Family members or strangers can exercise sexual violence in any settings of their choice. Its worst form is rape, that can be committed by a single male or group of males (gang rape) and the victim can be of any age, i.e. a young girl, adolescent or grown up woman. Sexual violence can be termed differently for instance, sexual assault, rape, sexual abuse. But these terms can be used according to the situations differently or interchangeably (WHO, 2003).

\section{Review Literature}

Women have always been considered as the property of men, therefore women have always faced violence and oppression. Their low status in the society allows men to use violence against them. Status of women varies in different parts of the world due to 
various factors (Pakeeza, 2015). According to World Health Organization (WHO), one out of three women face physical and sexual abuse and majority of the cases remain unreported (Qaisarani et al., 2016). The UN claims that violence against women starts even before their birth, i.e. on sex identification a baby girl is even aborted and making Female infanticide very common. Women face discrimination and violence from their childhood to old age, which is a violation of fundamental human rights and causes them physical, psychological and sexual abuse. Marital life of a woman intensifies her problems. It is commonly observed in western and eastern societies. Patriarchal social structure, customs, traditions and gender discrimination leads to a society, where inequalities against women are continuously increasing (Pakeeza, 2015).

Babar argues that Pakistani culture is also male dominated and violence against women is caused due to various factors, which involves socio-cultural setup, customs and traditions, norms and values, because they are deep rooted in our society (Babar, 2007). Patriarchy is tracked down from the era of Indo-Pak Sub-continent and is still prevailing in Pakistani socio-cultural setup. Male dominance is more visible in rural communities, since they are deprived of getting access to resources and basic fundamental rights (Pakeeza, 2015). Many substantial efforts have been made regarding health and violence, but still we lack in having accurate knowledge, facts and figures regarding the subject. For instance, it is very obvious that women face violence, but the intensity of violence and women's exposure to various types of violence throughout their life remains unacknowledged, which definitely results in extreme health issues and even causes death (Guruge and Khanlou, 2004).

\section{Violence against Women in Historical Context}

Discrimination against women is present in all human societies, which deprives them from attainment of their rights. History also reveals that women always had limited choices and had no control over their body and had no rights on her children, property, income and belongings, i.e. they were not given the right of decision making. Since they have no control of their life decisions, therefore, they are bound to accept what is decided for them by the males of their family. This male authority had led to violence and denial of their legal and social rights. In Indo-Pak Subcontinent, Muslim societies used to prefer traditions and customs over the religious laws, which had a negative impact. Due to mix cultural living in this region, people of different religions adopted customs and traditions of other cultural groups gradually. Status of women in Hinduism gradually impacted the Muslim societies, thus lowering the status of Muslim women as well. Denial of women's rights made them submissive in nature (Joseph, 2005). Socially constructed gender roles are basically the root cause of gender discrimination in Muslim Communities. Different socio-cultural factors play their role in designing social status of women (Federal Research Division, Library of Congress, 2005). When some social practices became common or legalized, due to social acceptance than it is not an easy task to eradicate it 
and in such male dominated societies, violence is not considered as the violation of women's rights. Thus, violence becomes the acceptable behaviour of the society society due to social setup (Galtung, 1990).

\section{Violence against Women in Pakistan}

Pakistan being a Muslim ideological state has the constitution and laws based on the Quran and Sunnah (Brass \& Vanaik, 2002). But, it is not pre-dominantly Islamic, because the cultural influence by other cultures and religions due to mix cultural living is very dominant. In Pakistan, cultural setup deviate us from Islamic teachings to a certain extent and adopting such social practices, which can clearly be called as evil practices for example, honor killing etc. (Warner, 2012). Visible male domination can be seen in all aspects of life for example, legal matters, family matters, religious aspects, politics, socio-cultural practices and economic matters (Kugelmass, 2004). In household setup, especially in a rural setup domestic violence is considered as a family matter, which cannot be intervened by any authority and reporting of domestic violence cases is also not a common practice in Pakistan (Fikree and Bhatti, 1999). Low social status of women enables men to treat them unfairly; these social and cultural norms are so engrossed in our society that we are unable to identify its limit and extent (Bettencourt, 2000).

Violence against women in all its worst forms has negative impact on Pakistani society; women are given no importance as human. Thus, the social structure is also deteriorating; especially the rural women suffer the most. Many social customs are practiced in Pakistan like, honor killing, Wani, Sawara, Wattasatta, etc., these customs are capturing and harming women's entire being (Kugelmass, 2004). The cultural influence from other religions has overshadowed the rights and status of women in Muslim societies instead of having dominated Islamic ideological society. In Pakistan, male dominance is promoted to a collective level through procedures and functioning of existing laws, customary laws and norms, self assumed religious interpretations and representing the false image of society.

\section{Distinguishing between Violence and Disciplinary Act}

Violence against women is misquoted by depicting wrong interpretation of verse 34 of Surah Nisa. It is misinterpreted by saying that in Quran, Allah has permitted to beat women if they disobey. There is a very fine line between understanding this verse correctly, i.e. there is a difference in admonishment and beating a wife on her actions. Verse 34 clearly states that there are certain steps which should be followed in case of disciplining a disloyal wife on her misconduct. This verse cannot be used to support the male domination or to give him authority to treat women as they want. Such false interpretation will be considered as misinterpreting the Holy Quran (Hendricks, 1988). In 
Holy Quran specific word for beating is used in Arabic as "daraba", which means separating or departing and in the Holy Quran, out of 16 times it is used in 9 places (Hathout, 2014). Besides this specific word, in the Holy Quran, in several verses, Allah says to respect and love your spouses and treat them well without harming them. AlHabri (2000) asserts to treat women nicely and husband should resolve the issues regarding disciplinary actions by using his authority, but only in extreme cases. But even in such cases, women should not be mistreated, things should be sorted out in proper manner in a civilized way (Al-Bukhari, vol. 8: Hadith 68). The Quran has pronounced very clearly regarding the issue, because it is mandatory for men to provide maintenance to their wives and to protect them. On the other hand it is obligatory for women to maintain their chastity even in their husband's absence they should remain a righteous wife. If a wife disobeys then husband can use his authority, but that too according to the shariyah, because beating a wife is always discouraged in Islam (MacFarquhar, 2007). Culture of any region is usually influenced by other religions and their cultures. Similarly, Pakistan being an Islamic state has Islamic principles and laws, but culturally we see that Pakistani society is also influenced and is not purely Islamic, in a way that people practice social practices which are not Islamic at all and it is a total violation of human rights for example tribal-culture, which is definitely pre-Islamic and some other customs like Wattasatta, Wani, Sawara, etc. (Pakeeza, 2015). Muslim and non-Muslim both societies portray almost same characteristics regarding women's low status. The picture of women's status is almost the same throughout the world; therefore, at international level various steps were taken to uplift their status and to control the violent and discriminatory acts against them.

CEDAW is one among such efforts to tackle the issue of violence, hence, in 1991, CEDAW recognized VAW as a global issue due to the pressure from women's groups, and in 1993, declaration was passed UN regarding Elimination of Violence against Women (Azhar et al., 2012). The issue of violence against women is growing in those societies where male dominance is a social norm and women are considered as a property of men (Babur, 2007). In the present age, violation of human rights prevails in its worst form in every country, class, race, ethnicity, culture and age (Azhar et al., 2012). When male dominance combines with social differences, it becomes the worst form of VAW (Bunch, 1990). This situation can occur anywhere, i.e. within the domestic domain, workplace, public places and even in prison. WHO has exposed that VAW exists in all societies, in all countries. It has also reported that VAW is lower in western and European countries because of high GDP and GNP growth (WHO, 2013). In the fourth world conference on women in 1995, the secretary general of the UN declared that gender equality is a very defining development, but still a lot is needed to be done, especially a legal response of the international human rights system to curtail violence against women (Edwards, 2011). 
Violence can be sub-divided into three categories as direct violence when women are killed in the name of honor killing by a relative, and it is structural violence when many other men are also involved in killing act, whereas it is societal violence when communities become least bothered on such acts of violence. According to Babar, Pakistani society reflects the image of cultural violence. In Pakistan dowry appears to be another form of violence against women in the form of humiliation, because girls are chosen by their in laws on the weightage of dowry (Babar, 2007). Dowry custom is common not only in urban areas, but also in rural areas and this custom persists due to typical mindset. Demanding dowry is due to many reasons like groom's family thinks that this way they can earn again what they have invested on their son or to impress their community by showing off the dowry. Whereas, in Islam it is otherwise, i.e. dowry is the right of a bride and groom is responsible to give dower as a gift to his bride in cash or kind or property etc. (Babur, 2007).

\section{Methodology}

This study examines the level of violence, exploitation and it also attempts to provide a clear understanding of the qualitative exploration of violence against women regarding social and cultural trends among women in Pakistan; therefore, to acquire in-depth study qualitative research method and descriptive survey method has been used by interviewing victims directly or their relatives to establish clear understanding regarding the topic to reproduce material from reliable sources and references to understand and decipher existing material. For this purpose case studies research methods is used to analyze specific issues within the boundaries of a specific environment and situation, because case study research method is explanatory, descriptive and exploratory in nature. In this study five case studies are incorporated to access the history and current scenario regarding violence against women in Pakistan by using unstructured interview schedule. Two private and government hospitals in Karachi, i.e. Patel Hospital and Civil Hospital were selected as a universe of the study, and the respondents were purposively selected for conducting interviews in detail. Descriptive method is used to get the insight and exact situation about the violence and exploitation faced by women from all walks of life to highlight the social and cultural aspects, which affects them physically, mentally, socially, culturally and psychologically. Since VAW is a burning issue therefore, it was quite a challenge to interview victims and directly or their relatives from all provinces. This study aimed to find out the overall scenario in Pakistan regarding violence against women. In Pakistan very few hospitals provide the facility to deal violence victims, especially burn victims, thus, these two hospitals (Patel Hospital and Civil Hospital) were chosen as universe to interview the violence victims, because they offer complete care for violence victims and patients from all over Pakistan are treated here. Hence the purpose of the study to interview respondents from all provinces was served. 


\section{Study Purpose}

The goal of this study is the qualitative exploration of violence against women (VAW) regarding social and cultural trends among women in Pakistan. The study aims to highlight the trends of violence throughout the life of women and to explore the causes which remain invisible.

\section{Case Studies}

Research based on case studies creates a clear understanding about complicated issues and entities, and it also strengthens the knowledge and experience, which is gained already from previous researches. Case studies are subjected to provide detailed analysis of an individual person, group of people, event(s), community/communities and relationships. This research method is used in a variety of disciplines to obtain in-depth knowledge. Social scientists use qualitative research method to analyse real-life conditions in order to understand the issue more closely. Case study is an empirical investigation technique to explore the phenomenon with unclear evidences. Case study method is used to gain in-depth knowledge of events or situations based on:

- Complete understanding of the event(s)

- Detailed description of the event(s)

- Analyzing event(s) holistically within the context

In case studies a variety of data tools are used, for example, interviews, survey method, research questionnaire, data analysis, observation and document reviews. Following the research ethics respondents and their families were assured that their real names and details will be kept secret and this information will not be handed over to print or electronic media (Yin, 2012). Case study method is purposively chosen to acquire each and every minute detail of violence victims in order to find out the root causes regarding the subject. Since the aim of this study was to cover the violence scenario all over Pakistan; therefore, respondents of different ethnicity were interviewed by visiting different wards of selected government and private hospitals. Some respondents were in a condition to give interview themselves and some interviews were conducted from the victim's relatives. The researcher maintained contact with the respondents even after getting discharge from the hospital through phone, social websites, Skype and emails, in order to seek answers of queries if needed. The respondents belong to different ethnic regions of Pakistan, but only few hospitals have special wards to treat burn or acid victims. 


\section{Case Study 1: Domestic Violence: Karachi}

Violence against women has become a global issue, which is caused by a series of factors, among which poverty, social injustice, gender inequality and a typical mindset of patriarchal societies are the key factors. Domestic violence is very common, but it is considered as a private issue or a family affair; therefore, it is not taken as a threat to women's life. These social attitudes help in the expansion of such social evils. Many women become the victim of domestic violence by their intimate partners, and our society remains silent for considering it as a private matter. Saira is one among such victims who faced violence by her husband. She got married at the age of 20 years; in early days of marriage her husband seemed to be a kind and loving person, but just after one year of marriage he lost the job and his frustration initiated arguments between them, which lead to violence later. First she thought to leave him, but her parents refuse to support her in case of divorce. After six years of marriage and abuse by her husband, Saira finally decided to seek help from a welfare centre or shelter home, because now she had a daughter with her, whom she wants to provide a safe environment. With the help of her neighbor, Saira moved to a shelter home and the incharge took her to a doctor to Civil Hospital Karachi for physical and psychological treatment. After few sessions she felt better and came out of that trauma and is now recovering. With the doctor's permission the researcher took her interview. During the interview session she told that sometimes her husband used to beat her even on petty things even after promising to behave properly. The staff of the shelter home provided her food, shelter and clothing. After gaining her confidence again she filed a divorce case against her husband and started a job to take care of her child. Saira told that sometimes her husband becomes so violent that he even used to beat his own four years old daughter. She advises women, do not let anyone hurt or exploit you; she wants women to be brave and to take steps to protect themselves. Besides that, she emphasized on awareness, because most of the women are unaware about the escape routes from such situations. These cases show that violence against women and children distorts not only their physical but psychological health as well; therefore, there should be a community-based support system to protect women from being victimized by their male counterparts and other family and community members.

\section{Case Study 2: Burn Victim: Sindh}

Violence against women has increased due to the legacy of institutionalized discrimination; therefore, now the government officials and policy makers have started to take serious measures to eradicate ethnical and gender discrimination, these policies will result only if they are implicated effectively. It is the responsibility of state to provide protection to women and should attempt to abolish gender inequalities and all other factors which are causing it. Efforts have been made on national and international level to 
control violence against women. CEDAW and Beijing Platform of Action and policies and legislation at national level can eradicate VAW by taking appropriate measures. Along with laws implementation, punishments should also be given, because punishment and penalty can control the issue to certain extent. Women face all types of violence due to the absence of effective policies and check and balance system. In Pakistan women face domestic violence either by their intimate partner or by in-laws. During this study a thirty years old woman named Perveen was interviewed in Civil Hospital Karachi, where she was brought for treatment from Sukhar, Sindh. She was victimized by her in-laws they attempted to burn her alive. She belongs to a middle class family and is the only child of her parents; she got married to Aqil just after completing her matriculation. Initially her in-laws used to treat her well. But after two years their attitude towards her started to change, because she could not bear a child due to medical complications. Her sister in-laws forced Aqil to marry again for a child, but he refused. This situation left no choice for her in-laws; they started to plan to get rid of her. Initially they accused her of bad character, but still her husband had faith in her and became angry on such cheap tactics of his sisters. Perveen's in-laws then decided to burn her alive and pretend it to be an accident. One day they trapped Perveen in the kitchen and set her on fire. That day Aqil by chance came home early and seeing the situation he tried to save his wife, but in the process he too got severe burns and could not survive, whereas, Perveen survived. Her face and both arms till shoulders were burnt, she had first degree burns; therefore, she remained out of danger. Thought she is alive, but her whole life is devastated now.

\section{Case Study 3: Acid Throwing: Punjab}

Violence cases against women are becoming very common. According to studies acid throwing cases are a result of refusal of love or marriage proposal from women, which shows that patriarchal society do not allow women to make decisions of their own. Maryam a nineteen years old girl became the victim of acid throwing and was brought to Patel Hospital Karachi from Lahore by her parents; she belonged to a very well off family and she happened to be a very pretty girl. She was living a very happy and content life and was busy in completing her O' Levels. It was an intentional act of acid burning and she had third degree burns. The culprit (Amjad) was the van driver who used to pick and drop her to the college. He started to develop a liking for her, but in a lust full manner, she ignored him and tried to avoid. She once told her mother about this, but her mother did not pay much attention as she has no idea that this could become so serious. But one day he told her clearly about his liking and Maryam refused him and stopped going in his van and told her parents about it. Then her father took the responsibility to pick and drop her to the college. One day she was standing at the college gate waiting for her father, suddenly that van driver appeared and asked her once again, she refused, then he flared up and threatened her, she was so afraid and just few days after this argument he threw acid on her face and body while she was waiting for her father at the college gate. 
She got severe burns and died after three weeks of the incident. Her father files a case against Amjad but police failed to arrest him. Acid throwing seems to be the easiest way of punishing women for the crimes and mistakes, which were never committed by them.

\section{Case Study 4: Honor Killing: Peshawar}

Patriarchal society does not allow women to live life based on their choices and decisions, but on the other hand when it comes to family's name and pride (khandaan ki izzat), women are considered as its custodian. Therefore, women have to face great burden not to bring any shame to the family, whereas a son has no such obligation. The term honor killing is referred as to punish a person who spoils family's name and pride, which seems to be the responsibility of women only. Farhana has been just another teenage girl, becoming the victim of our so called social customs, honor killing (ghairat ke naam per qatal). This interview was conducted from her mother after her death through Skype, because this case was referred by a doctor of Civil Hospital Karachi. Farhana's mother agreed to give interview, because she was very guilty for not been able to save her daughter. After the death of her father, her elder brother became the head of the household. Farhana and her mother being dependent on Ali (brother) could not decide anything on their own. After completing the graduation, she wanted to do the job. Her brother permitted but unwillingly, because he was not in favour of women to work. One of Farhana's colleagues (Asim) was interested in her; therefore, he perused her mother and brother for marriage proposal. Instead of marrying off her sister in a good manner, Ali flared up and doubted her of immoral character. The things started becoming complicated and one day Ali killed her own sister by burning her alive, because according to him she was bringing bad name to the family. The worst thing was that even her mother was unable to save her. She feels very guilty now, but has no strength to file a case against her own son. Honor killing is not controlled yet even after legislation by the assemblies at national level.

\section{Case Study 5: Rape Victim: Balochistan}

Violence against women is not an issue of one community, region or country. Even after legislations to control VAW, we see continuous increase of violence cases at national and global level. Sexual assault and rape cases have become the news headlines on daily basis. A sexual assault case of unmarried twenty four years old girl Sara Baloch was referred by Civil Hospital Karachi. Doctor convinced her father for an interview in order to raise voice on all possible forums. Sara was a daughter of a retired JCO (junior commissioned officer in Pakistan army), their native city is Quetta. She was raped by a man (Naseer) to take revenge for refusing his proposal. Naseer was a criminal and was even sent to jail twice therefore, her father refused to accept his proposal. After refusing his proposal Sara and her family thought that he will not harm them. But he was not that kind of person; he 
took the refusal as his insult and wanted to take revenge. He was only waiting for the right moment, and a week later he kidnapped Sara and raped her, and he also burned her entire body brutally with cigarette. She was physically mentally tormented. She is not only mentally upset but she also fear men and does not want to marry anyone now. Her parents and siblings support her fully and want to see her to lead a normal life again. These cases happen because culprit gets away even after committing such brutal crimes. Though Sara has survived, but the question arises that, the trauma Sara and her family has faced, can it be erased from their memories? And when the police will become efficient enough to arrest such culprits?

\section{Results and Discussion}

Creating understanding and awareness about VAW is more complex than it seems. Examining the literature shows that all of its explanations have contextual and cultural background. The violence phenomenon in the Pakistani context is evident from the theoretical perspective as well. This study has focused to cover intrinsic and extrinsic factors through social, economic, political and cultural setup in Pakistan. The majority of the women face violence by their intimate partners, or as a result of love or proposal refusal, including honor killing, bride burning and rape, etc. Along with that major contributor are the customs like Karo-Kari, Wani, Sawara, Wattasatta, etc. Violence of any form is a clear violation of fundamental human rights, which causes women social and economic issues along with physical and psychological problems.

In Pakistan, on public and private sector level no such efforts are done to establish a balanced society possessing balanced relationship; therefore, instead of improvement, social deterioration is becoming more common. It is an urgent need of the time to conduct enough researches to explore all known and unknown aspects of the problem. Eradication of social evils is possible only when serious efforts with appropriate policies will be practiced. There are extrinsic and intrinsic factors involved in violence against women. Extrinsic factors include male's authority within the family, economic dependency on males and verbal conflicts, etc. Patriarchy seems to be the main determinant of violence against women, because women do not have decision making power or control over their bodies and lives. In patriarchal societies like Pakistan, males are considered head of the household and women have no authority at all, they cannot even decide anything for their children. At this point women consider themselves socially isolated, helpless, powerless, insecure and incomplete and bungling without men. This social scenario makes women a very easy victim for the perpetrators. Domestic violence within the marital relationship gives men full authority to treat women as they want. Women are deprived and disgraced by their own intimate partners. Women are considered as men's property and a commodity, 
whose role is submissive and has to sacrifice her life for her family. Before marriage, she has to maintain her family's pride and after marriage, she became the property of her husband. Only in few families dignity of woman is maintained, but then the other men become the perpetrator. As in case studies different scenarios are observed that females are mistreated by her brother or husband and if the family is supporting then in that case strangers become the perpetrator. Women's life is restricted either by extrinsic or intrinsic factors, either they face domestic violence from their husbands or in-laws or they become the victim of people with whom they have no relationship. This research analyzes that, man-made values, code of conduct and ethics are fulfilled at the cost of women's life.

\section{Conclusions}

Violence against women is a growing problem globally. Women from all cultural backgrounds, ethnicity, races, classes and region are affected due to violence and injustice within the society. Majority of the times violence cases have become life threatening for women, which is represented in this study through case studies. Practice of traditions and customs also causes violation of human rights, thus women being vulnerable part of the society are easily victimized. Violence not only disturbs their life, but also affects their health physically and psychologically. Violence against women has many dismaying forms, which includes: domestic violence, sexual abuse, rape, girl child marriage, female circumcision, acid throwing, burning to death and wife battering, which is a clear violation of fundamental human rights.

This study has been carried out to identify and evaluate the issues faced by the women due to social and cultural factors qualitatively. The study reveals that in the presence of legal cover and laws, women are exploited and face abusive behaviour from males within and outside the home. Which clearly indicates that implementing laws only is not enough to bring social change, for that purpose, we need to work on changing mindsets as well. Another reason of increase in the level of violence against women and exploitation is lack of awareness of rights among women in Pakistan. Their ignorance becomes the reason of their victimization, and due to lack of awareness they only seek rescue rather than complaining against the abusive behaviour of people around them. This study alone cannot cover all the aspects of VAW; therefore, further in-depth studies are required to explore all the root causes on the subject. These issues should be dealt on emergency bases in order to protect women from violence of all kinds, otherwise cases like Zainab of Qusoor and such other incidents will take place repeatedly and women and girls will become more vulnerable against these social evils. 


\section{Limitation and Delimitations}

Since the aim of this study was to find out the overall scenario regarding violence against women in Pakistan, therefore it was quite a challenge to interview respondents from all the provinces because in Pakistan such cases are not reported. Somehow, it became possible to interview respondents belonging to different ethnicity, by visiting different wards of government and private hospitals and by interviewing the relatives of victimized women directly or by using social websites, Skype and emails. Violence against women is a deep rooted social and cultural aspect, therefore reaching respondents and interviewing them was not an easy task. By using personal links and assistance, interviewing became possible. Respondents and their families were assured that their real names and details will be kept secret and this information will not be handed over to print or electronic media.

\section{Recommendations}

To combat violence against women some serious efforts are needed, which should be systematic, well-coordinated and sustainable.

- Existing laws regarding human rights and violence against women should be amended to enhance the promotion and protection of women in Pakistan.

- International laws and agreements should be implemented strictly to assure the protection of women.

- Budget allocation in a substantive amount is needed to help out the women who are victimized, to provide urgent help in economic and medical urgency.

- According to the constitution of Pakistan liberty, protection and legal aid should be provided urgently to deal the matter as quickly as possible in order to maintain social justice.

- It is the obligation of government to provide legal aid to every citizen to protect their lives, which is their fundamental right.

- Laws regarding violence against women and their protection should be adequately implemented.

- Free and one window legal aid system should be introduced at district level.

- Government and private sector should make collaborative efforts to curtail violence against women.

- Awareness campaigns and seminars should be conducted at local level, to raise the level of awareness regarding rights among women. 
- Education and awareness programmes can help in changing the mindset of people, because violence against women is deeply rooted in our society and culture.

- Social injustice, discrimination and gender biases can only be overhauled by appropriate interventions at all levels.

\section{References}

Agarwal, B. (1988). Structures of Patriarchy: State, Community and Household in Modernizing Asia, London.

Agha, Nadia (January 04, 2017). Daily Dawn: In honour's name, Karachi, Pakistan, Dawn Publications.

Ahuja, Ram (1998). Violence Against Women, Delhi, India, Rawat Publications, p.11.

Al-Bukhari (English Translation): Hadith 68, vol.8, pp.42-43.

Al-Habri, A. (2000). An Introduction to Muslim Women Rights, Gisela Web ed. Syracuse University Press, p.51-71.

Ali, P. \& Gavino, M. (2008). Violence against Women in Pakistan: A Framework for Analysis, Journal of Pakistan Medical Association, vol.58:4, pp.198-203.

Al-Quran: Surah 4: Ayah 1.

Al-Quran: Surah 4: Ayah 32.

Al-Quran: Surah 4: Ayah 34.

Aurat Foundation (2012). Researching Aspects of Gender Based Violence in Pakistan, Pakistan, Aurat Foundation Publication and Information services foundation, Gender Equity Program, p.1.

Azhar, Z. et al. (2012). Exploring Socio-Economic Factors Behind Domestic Violence Against Women in Sargodha District, International Journal of Asian Social Science, vol.2:9, pp.1617-1626.

Azim, S., Naved, R., Persson, L. and Bhuiya, A. (2002). Women's Health and Domestic Violence Against Women in Bangladesh, Dhaka, Urban Primary Health Care Project-Asia Development Bank. 
Babur, Z. (2007). Violence Against Women in Pakistan: Current realities and strategies for change, European University Center for Peace Studies Stadtschlaining/Burg, Austria, pp.10-21, 31, 39.

Begum, A. \& Shiplu, K.D. (2013). Domestic Violence against Women in Bangladesh: A Critical Overview, The Chittagong University Journal of Law, vol.7, pp.105-129.

Belsky, J. (1980). Child Maltreatment: An Ecological Integration, Am Psyc, vol.35, pp.320-335.

Bettencourt, A. (2000). Violence against Women in Pakistan, Human Rights Advocacy Clinic; Litigation Report Spring.

Bettencourt, A. (2000). Violence against Women in Pakistan. Human Rights Advocacy Clinic; Litigation Report Spring.

Bradley, F., Smith, M., Long, J. \& O'Dowd, T. (2002). Reported Frequency of Domestic Violence: Cross Sectional Survey of Women Attending General Practice, BMJ, vol.324:7332, p.271.

Brass, Paul R. and Vanaik, Achin et al. (2002). Competing Nationalisms in South Asia: Essays for Asghar Ali engineer, Hyderabad, Orient Longman, p. 257.

Bunch, C. (1990). Women's Rights as Human Rights: Toward a Re-Vision of Human Rights, Human Rights Quarterly, vol.12:4, pp.486-498.

Campbell, J. \& Humphreys, J. (1993). Nursing care of Survivors of Family Violence (2nd ed.), St. Louis, Mosby-Yearbook.

Carlson, B. (1984). Causes and Maintenance of Domestic Violence: An Ecological Analysis, Social Service Review, vol.58, pp.569-587.

Citizenship and Immigration Canada (CIC). (2010). Facts and Figures 2006, Immigration overview.

Coker, A.L. et al. (2000). Frequency and Correlates of Intimate Partner Violence by Type: Physical, Sexual, and Psychological Battering, Am J Public Health, vol.90, pp.553-559.

Dasgupta, S.D. (2001). Towards an Understanding of Women's Use of Non-Lethal Violence in Intimate Heterosexual Relationships, Applied Research Forum, National Electronic Network on Violence Against Women. 
Dutton, D.G. (1994). Patriarchy and wife assault: The ecological fallacy, Violence Vict, vol.9, pp.167-182.

Edleson, J.L. (2000). Primary Prevention and Adult Domestic Violence, Paper Presented at the Meeting of the Collaborative Violence Prevention Initiative, San Francisco.

Edleson, J.L. \& Tolman, R.L. (1992). Intervention for Men who Batter: An Ecological Approach, Newbury Park, CA, Sage Publication.

Edwards, Alice (2011). Violence Against Women: Under International Human Rights Law, New York, Cambridge University Press, p.1.

Ellsberg, M., Pena, R., Herrera, A. et al. (1999). Wife abuse among women of childbearing age in Nicaragua, Am J Public Health, vol. 89, pp. 241-244.

European Union Agency for Fundamental Rights (2014). Violence against Women: An EU-wide survey, Europe, European Union Agency for Fundamental Rights, p.71.

Federal Research Division, Library of Congress (2005). Report: Women In Islamic Societies: A Selected Review of Social Scientific Literature, USA, Federal Research Division, Library of Congress, p.1.

Felix, Q. (2007). Honour killing and "karo kari" in Pakistan, Available at http://www.asianews.it/news-en/Honour-killing-and-Karo-Kari-in-Pakistan1187.html.

Feroz, Rehana (December 27, 2017). Daily Baluchistan Express: Domestic Violence Against Women in Pakistan, Quetta, Baluchistan, Pakistan, Baluchistan Express.

Fikree, F. and Bhatti, L.I. (1999). Domestic violence and health of Pakistani women, International J Gynaecol Obstet, vol.65, pp.195-201.

Galles, R.J. and Cornell, C.P. (1985). Intimate violence in families, Beverly Hills, Sage Publications.

Galtung, J. (1990). Cultural Violence, Journal of Peace research, vol. 27:3.

General Assembly (1993). United Nations Declaration on the Elimination of Violence Against Women, General Assembly, UN. 
Gondolf, E.W. \& Fisher, .ER. (1988). Battered Women as Survivors: An Alternative to Treating Learned Helplessness, Lexington, MA, Lexington Books.

Hadi, S.T. (2010). The Face of Intimate Partner Violence in Bangladesh: Revealing Patterns from the Existing Literature, Bangladesh e-Journal of Sociology, vol.7, pp.12-20.

Hanif, Intikhab (February 25, 2016). Daily Dawn: PA Approves Bill for Protection of Women against Violence 2015, Pakistan, Dawn Publishers.

Hathout, Summer (2014). Don't Hold All Muslims Responsible for Men Who Misuse Quran, Beat Women, Muslim Women's League, LA Daily Journal Available at: http://www.mwlusa.org/topics/violence\&harrassment/domesticviolence.htm

Heise, L., Ellsberg, M. \& Gottemoeller, M. (2002). A Global Overview of Gender-Based Violence, Int J Gynecol Obstet, vol.78:1, pp.5-14.

Heise, L.L. (1998). Violence against women: an integrated, ecological framework, Violence Against Women, vol.4, pp.262-290.

Hendricks, Shaykh Seraj (1988). A Study in the Understanding of Authority and the Abuse of Power in Muslim Marriages, (Presented at the Women's Conference of the 2nd International Islamic Unity Conference in Washington DC, 8 August 1998, Omni Shoreham Hotel, Blue Room.

HRCP. (2016). Annual Report: State of Human Rights in 2016, Pakistan, HRCP.

Human Rights Commission of Pakistan (HRCP). (2000). State of human rights in 1999, Lahore, Pakistan, HRCP.

Human Rights Watch (1999). Crime or Custom? Violence against Women in Pakistan: Report of Human Rights Watch 1999, USA, Human Rights Watch, Available at: URL: http://www.hrw.org/reports/1999/pakistan/index.htm

Jahan, R. (1994). Hidden Danger: Women and Family Violence in Bangladesh, Dhaka, Women for Women.

Jewkes, R. (2002). Intimate Partner Violence: Causes and Prevention, Lancet, vol.359, pp.1423-1429. 
Joseph, Saud et al. (2005). Encyclopedia of Women and Islamic Cultures: Family Law and Politics - Volume -2, Boston, MA: Brill, pp.433-434.

Kabeer, N. (1998). Money Can't Buy Me Love? Evaluating Gender, Credit and Empowerment in Rural Bangladesh, Bangladesh, IDS.

Khan, M.E. and Aeron, A. (2006). Prevalence, Nature, and Determinants of Violence against Women in Bangladesh, The Journal of Family Welfare, vol.52, pp.33-51.

Khan, R. (2009). Situational Analysis and Mapping of Women's Human Rights in Pakistan, Pakistan, Report Gender Equity Program (GEP) USAID/Aurat Foundation.

Khatun, M.T. and Rahman, K.F. (2012). Domestic Violence against Women in Bangladesh: Analysis from a Socio-legal Perspective, Bangladesh e-Journal of Sociology, vol. 9, pp. 19-30.

Krug, E.G., Mercy, J.A., Dahlberg, L.L. \& Zwi, A.B. (2002). The World Report on Violence and Health, Lancet, vol.360, pp.1083-1088.

Kugelmass, Judy W. (2004). The Inclusive School: Sustaining Equity and Standards, New York, Teachers College Press, pp.13-14.

MacFarquhar, N. (2007). New Translation Prompts Debate on Islamic Verse, New York, USA, The New York Times.

Maxwell, S. R. and Blair, S. L. (2015). Violence and Crime in the Family: Patterns, Causes, and Consequences, Emerald Group Publishing Ltd., p. 101.

Naved, R.T. (2013). Sexual Violence towards Married Women in Bangladesh, Archives of Sexual Behaviour, vol. 42, pp. 595-602.

Pakeeza, S. (2015). Domestic violence laws and practices in Pakistan, VFAST Transactions on Education and Social Sciences, vol.6:1, pp.17-20.

Qaisarani, A. et al. (2016). Socio-economic and Cultural Factors of Violence against Women in Pakistan, SDPI.

Raphael, B. (2000). Domestic violence, Med J Aust, vol.173, pp.513-514.

Rennison, C. (2003). Intimate Partner Violence, 1993-2001, Washington (DC), Bureau of Justice Statistics, Department of Justice (US), Publication No. NCJ197838. 
S., Guruge and N., Khanlou (2004). Intersectionalities of influence: researching health of immigrant and refugee women, Canadian Journal of Nursing Research, vol.36:3, pp.32-47.

Saltzman, L.E., Fanslow, J.L., McMahon, P.M. and Shelley, G.A. (1999). Intimate Partner Violence Surveillance: Uniform Definitions and Recommended Data Elements, Version 1.0, Atlanta, National Center for Injury Prevention and Control, Centers for Disease Control and Prevention.

U.S. Department of State (2010). Human Rights Report, Pakistan, U.S. Department of State.

UNICEF (2017). Is every child counted? Status of Data for Children in the SDGs, UNICEF, p. 54.

United Nations Office on Drugs and Crime (2014). Global Study on Homicide 2013, UN Office, United Nations Office on Drugs and Crime, p.14.

Warner, Judith Ann (2012). Women and Crime: A Reference Handbook, Santa Barbara, California, ABC-CLIO, pp.131-132.

Watts, C. and Zimmerman, C. (2002). Violence against Women: Global Scope and Magnitude, Lancet, vol.359, pp.1232-1237.

White Ribbon Pakistan (2015). Statistics of VAW, Pakistan, White Ribbon Pakistan.

World Health Organization (WHO). (1996). Violence against Women, WHO Consultation, Geneva, WHO.

World Health Organization (WHO). (1997). Violence against Women, A Health Priority Issue, Geneva.

World Health Organization (WHO). (2002). WHO Report on Violence and Health, Geneva, World Health Organization.

World Health Organization (WHO). (2003). Guidelines for Medico-Legal Care for Victims of Sexual Violence, Geneva, The World Health Organisation.

World Health Organization (WHO). (2013). Global and Regional Estimates of Violence against Women: Prevalence and Health Effects of Intimate Partner Violence and Non-Partner Sexual Violence, London, Department of Reproductive Health and Research, London School of Hygiene and Tropical Medicine, South African Medical Research Council, p.2. 
World Health Organization (WHO). (2013). Violence against Women The Health Sector Responds, Geneva, The World Health Organisation, p.16.

Yasmin, L. (2000). Law and Order Situation and Gender-based Violence: A Bangladesh Perspective, Colombo, Regional Centre for Strategic Studies.

Yin, Robert K. (2012). Applications of Case Study Research (ed. 3), Los Angeles, USA, Sage Publications, pp.3-6, 9-10.

Zaidi, Hassan Belal (October 07, 2016). Daily Dawn: Anti-Honour Killing, Anti-Rape Bills Finally Passed, Pakistan, Dawn Publishers.

Seema Manzoor is Lecturer in the Centre of Excellence for Women's Studies, University of Karachi.

Dua-e-Rehma is Lecturer in the Centre of Excellence for Women's Studies, University of Karachi.

Prof. Dr. Naheed Abrar is Chairperson in the Department of Social Work, Federal Urdu University, Karachi. 